\title{
BMJ Open How self-stigma affects patient activation in persons with type 2 diabetes: a cross-sectional study
}

\author{
Asuka Kato (D) , ${ }^{1}$ Yuko Fujimaki, ${ }^{2}$ Shin Fujimori, ${ }^{2}$ Akihiro Isogawa ${ }^{3}$ Yukiko Onishi, ${ }^{4}$ \\ Ryo Suzuki (D) , ${ }^{5}$ Kohjiro Ueki, ${ }^{5}$ Toshimasa Yamauchi, ${ }^{5}$ Takashi Kadowaki, ${ }^{5}$ \\ Hideki Hashimoto ${ }^{1}$
}

To cite: Kato A, Fujimaki Y, Fujimori S, et al. How self-stigma affects patient activation in persons with type 2 diabetes: a crosssectional study. BMJ Open 2020;10:e034757. doi:10.1136/ bmjopen-2019-034757

- Prepublication history and additional material for this paper are available online. To view these files, please visit the journal online (http://dx.doi. org/10.1136/bmjopen-2019034757).

Received 04 0ctober 2019 Revised 13 March 2020 Accepted 03 April 2020

\section{Check for updates}

(C) Author(s) (or their employer(s)) 2020. Re-use permitted under CC BY-NC. No commercial re-use. See rights and permissions. Published by BMJ.

${ }^{1}$ Department of Health and Social Behavior, School of Public Health, The University of Tokyo, Tokyo, Japan

${ }^{2}$ Department of Internal Medicine, School of Medicine, Teikyo University, Tokyo, Japan ${ }^{3}$ Diabetes Care Division, Mitsui Memorial Hospital, Tokyo, Japan ${ }^{4}$ Division of Diabetes and Metabolism, The Institute for Adult Diseases, Asahi Life Foundation, Tokyo, Japan ${ }^{5}$ Department of Diabetes and Metabolic Diseases, Graduate School of Medicine, The University of Tokyo, Tokyo, Japan

Correspondence to

Dr Asuka Kato;

asukakato-tky@umin.ac.jp

\section{ABSTRACT}

Objectives Self-stigma is associated with lower patient activation levels for self-care in persons with type 2 diabetes mellitus (T2DM). However, the causal pathway linking self-stigma with patient activation for self-care has not been shown. In order to determine how self-stigma affects patient activation for self-care, we tested a twopath hypothetical model both directly and as mediated by self-esteem and self-efficacy.

Design A cross-sectional study.

Setting Two university hospitals, one general hospital and one clinic in Japan.

Participants T2DM outpatients receiving treatment $(n=209)$ completed a self-administered questionnaire comprising the Self-Stigma Scale, Patient Activation Measure, Rosenberg Self-Esteem Scale, General SelfEfficacy Scale, Patient Health Questionnaire, haemoglobin A1c test, age, sex and body mass index.

Primary and secondary outcome measures Self-stigma levels were measured by using the Self-Stigma Scale. Patient activation levels were measured by the Patient Activation Measure.

Results Path analysis showed a strong relationship between self-stigma and patient activation $\left(\chi^{2}=27.55\right.$, $\mathrm{p}=0.120$; goodness-of-fit index $=0.97$; adjusted goodnessof-fit index=0.94; comparative fit index=0.98; root mean square error of approximation=0.04). Self-stigma had a direct effect on patient activation $(\beta=-0.20 ; p=0.002)$. Indirectly, self-stigma affected patient activation along two paths $(\beta=0.31 ; p<0.001)$ by reducing self-esteem $(\beta=-0.22 ; p<0.001)$ and self-efficacy $(\beta=-0.36$; $\mathrm{p}<0.001$ ).

Conclusions Due to the cross-sectional design of the study, longitudinal changes between all the variables cannot be established. However, the findings indicate that self-stigma affected patient activation for self-care, both directly and as mediated by self-esteem and self-efficacy. Interventions that increase self-esteem and self-efficacy may decrease self-stigma in patients with T2DM, thus increasing patient activation for self-care.

\section{INTRODUCTION}

The incidence of type 2 diabetes mellitus (T2DM) is increasing worldwide. ${ }^{1}$ These patients are generally treated on an outpatient basis, and many individuals may require
Strengths and limitations of this study

- This quantitative study is the first detailed examination on how self-stigma affects patient activation for self-care.

- All efforts were made to include all variables related to self-stigma including various self-concepts that explain the model despite the limitations that a cross-sectional study design may cause.

- The strength of this study is that it provides practical targets for possible intervention such as selfesteem, self-efficacy and self-stigma in order to improve patient activation for self-care.

advice and support from their physicians to effectively self-manage their care. Adherence to recommended self-care behaviours, particularly those involving diet, exercise and medication regimes, is critical in the prevention of serious morbidity or mortality in patients with T2DM. ${ }^{23}$ Those who understand the importance of self-care behaviours in daily life are better equipped to gain the knowledge, skills and confidence necessary to actively engage in their own treatment. ${ }^{4} 5$ Consequently, enhancing patient activation for self-care and ameliorating factors that discourage selfactivation for care may encourage patients to fully and actively engage in self-care. Patient activation is defined as patients' selfengagement in treatment which consists of a number of elements related to activation. This may include knowledge, skills, confidence and behaviours that patients need to manage their illness. ${ }^{45}$

In many societies, individuals with T2DM are negatively stereotyped because T2DM is considered to be a lifestyle-related disease. This can lead some patients to blame themselves for their condition. ${ }^{6} 7$ The associated stigma-whether experienced or perceivedmight discourage patient activation for selfcare. Indeed, self-stigmatisation in persons 
with T2DM has been associated with the tendency to vary from prescribed treatment regimens due to a desire to avoid social situations that may trigger blame and judgement by others. ${ }^{7}$ Self-stigma is defined as internalised stigma wherein individuals develop negative and prejudicial attitudes toward themselves because of their condition by either experiencing stigma or perceiving stigma. ${ }^{8-11}$ In a previous study, self-stigma was found to be a significant predictor of lower patient activation levels for self-care in persons with T2DM. ${ }^{8}$ However, the causal pathway linking self-stigma with patient activation has not been shown.

Self-stigma has been shown to impact the behavioural goals of general psychiatric patients by reducing both self-esteem and self-efficacy. ${ }^{9-11}$ In the context of diabetes care, and specifically the care of persons with T2DM, the causal pathway linking self-stigma with patient activation has not been shown. This is the case particularly in terms of other psychological factors involved, such as self-esteem and self-efficacy. Here, we define self-esteem as the degree to which people have a favourable (or unfavourable) opinion of themselves and find themselves worthy (or unworthy) overall. Health status is thought to be a component of self-esteem. ${ }^{12}$ We define self-efficacy as one's belief in their general personal ability to succeed in specific situations, perform certain tasks or develop certain behaviours. ${ }^{13}$ Thus, in the present study, we examined general self-efficacy in individuals with T2DM, together with the degree to which it included diabetes self-management behaviours. Depressive symptoms are also related to self-stigma. Previous studies show that self-stigma is negatively associated with self-concepts, consequently resulting in greater levels of depressive symptoms. ${ }^{8-11}$ Different facets of self-concepts include self-esteem and self-efficacy.

Controlling public stigma regarding T2DM at the societal level represents a considerable challenge. At the individual level; however, addressing the effect of self-stigma on patient activation could be helpful in encouraging and maintaining patient activation. Indeed, although self-stigma has been found to be associated with lower patient activation levels for self-care, appropriate intervention strategies have not been determined. ${ }^{8}$ Developing specific interventions to reduce self-stigma in persons with T2DM requires an understanding of the process by which self-stigma, in conjunction with other factors, leads to lower patient activation. A better understanding of the mechanisms by which self-stigma affects patient activation may aid healthcare professionals in specifically managing patient self-care behaviours, leading to improved treatment outcomes. Therefore, based on the findings from previous studies, ${ }^{8-11}$ we evaluated the contributions of self-esteem and self-efficacy to self-stigma in persons with T2DM, with the goal of understanding how these factors influence patient activation for self-care.

Here, we examined the exact nature of the mechanism that links self-stigma and patient activation. Based on earlier studies, ${ }^{8-11}$ we hypothesised that self-stigma might affect patient activation not only directly, but also indirectly by reducing self-esteem and self-efficacy.

\section{METHODS}

\section{Participants}

We collected cross-sectional data via a questionnaire. The sampling method was described previously. ${ }^{8}$ Briefly, we used consecutive sampling, recruiting all outpatients with T2DM who visited an endocrinologist on a specific date at any one of four locations in Japan: two university hospitals, one unaffiliated hospital and one unaffiliated clinic. Participants were recruited through their endocrinologists, and after explaining the study purpose to the participants, informed consent was obtained from all participants included in the study. The inclusion criteria were presence of T2DM, age 20-74 years and ability to read and speak Japanese. Exclusion criteria were diagnosis of type 1 diabetes, dementia and/or psychosis and urgent need of a medical procedure. Participants completed a pen-and-paper questionnaire that was administered by research staff. It took approximately $20 \mathrm{~min}$ to complete.

\section{Measures}

We collected the following sociodemographic information from the participants: age, sex, education (in years) and marital status. We also collected clinical information, including body mass index (BMI; calculated as weight in kilograms divided by height in metres squared), time (in years) since diagnosis of T2DM, primary treatment (oral hypoglycemic agent and/or insulin injection, other injectable medication or lifestyle changes), diabetes-related complications and haemoglobin A1c level (HbAlc) as measured in a laboratory on the day of the questionnaire. HbAlc is a blood test used to assess a person's glycaemic control, and provides information about the average levels of blood glucose over the past 1-2 months. We calculated the number of diabetes-related complications as the simple sum of six complications (score 0-6), referring to the Diabetes Complications Index. ${ }^{14}$

\section{Self-stigma}

We used the Self-Stigma Scale to assess levels of selfstigma. ${ }^{15}$ The 39-item Japanese version of the scale (SSS-J) was validated in a previous study. ${ }^{16}$ Responses to each item are given using a 4-point Likert scale (score $0-3$ : strongly disagree, disagree, agree and strongly agree, respectively). Total score (range $0-117$ ) is treated as a continuous variable, with higher scores indicating higher self-stigma. In this study, internal consistency was 0.96 for the SSS-J.

\section{Patient activation}

We used the Patient Activation Measure (PAM-13) to assess levels of patient activation for engaging in self-care. ${ }^{17-19}$ We intentionally chose the PAM-13 because it takes into account not just single instances of self-managing behaviours (such as exercising or eating properly during 
a given week), but also a person's knowledge, skills, and beliefs in relation to managing their chronic illness. Conceptually, high patient activation entails several elements: patient knowledge, skills and confidence, as well as engagement in behaviours needed to manage their illness (here, T2DM). The PAM-13 predicts a range of comprehensive behaviours, including both general health maintenance behaviours (eg, exercise and diet) and disease-specific self-management behaviours (eg, keeping a written diary of glucose levels and taking diabetes medication as recommended by a personal physician). ${ }^{518}$ The PAM-13 is used in clinical settings, and is a highly reliable, valid scale. It comprises 13 questions scored using a 4-point Likert scale (score 1-4: strongly disagree to strongly agree), for a total score of 13-52. We converted the scores to an interval scale (0-100) according to the scoring algorithm. ${ }^{18}$ Higher scores indicate a more positive attitude toward the behavioural changes necessary for effective intervention. We used the Japanese version of the PAM-13 for mental health, which does not include the words 'mental health,' as requested by the scale's developer. In this study, the internal consistency of the PAM-13 was 0.85 .

\section{Self-esteem}

We used the Rosenberg Self-Esteem Scale to assess selfesteem. ${ }^{12}{ }^{20}$ The scale is widely accepted, with high reliability and validity. It consists of 10 items that are scored using a 4-point Likert scale (score 1-4: strongly disagree to strongly agree). After item scoring, five negative items are inverted and all scores are summed. In this study, the internal consistency of the Rosenberg Self-Esteem Scale was 0.79 .

\section{Self-efficacy}

We used the General Self-Efficacy Scale to assess strengths in general self-efficacy across a variety of settings in everyday life. ${ }^{21}$ This scale uses 16 dichotomous (yes/ no) questions and is reliable, valid and commonly used to measure self-efficacy in Japan. The total score (range $0-16$ ) is treated as a continuous variable, with higher scores indicating higher self-efficacy. In this study, the internal consistency of the General Self-Efficacy Scale was 0.84 .

Previous studies have shown self-esteem and selfefficacy to be closely related to self-stigma. ${ }^{911} 16$ Thus, we purposefully chose the Rosenberg Self-Esteem Scale and the General Self-Efficacy Scale to address how various selfconcepts such as self-stigma, self-esteem, and self-efficacy affect activation for self-care in persons with T2DM.

Moreover, we are treating patient activation and selfefficacy as two significantly distinct terms based on the findings of Sakano et $a l^{21}{ }^{21}$ Fujita $e t a l^{17}$ and Hibbard $e t$ $a l^{18} 19$ Separating patient activation from self-efficacy also allows us to examine the degree to which general self-efficacy in individuals with T2DM included diabetesrelated self-management behaviours.

\section{Depression symptoms}

We used the nine-item depression module of the Patient Health Questionnaire (PHQ-9) to assess the presence and severity of depression symptoms during the 2-week period before the participants completed the questionnaire. $^{22} 23$ The PHQ-9 is a reliable and valid instrument for measuring the severity of clinical depression. We scored items according to the Diagnostic and Statistical Manual of Mental Disorders-IV criteria (score 0-3: not at all to nearly every day). Total score (range $0-27$ ) was treated as a continuous variable. In this study, the internal consistency of the PHQ-9 was 0.86 .

\section{Statistical analysis}

For continuous measures, we calculated means and SD. For other data, we used raw numbers and percentages. To elucidate the mechanism linking self-stigma with patient activation, and to evaluate potential mediation by self-esteem and self-efficacy, we determined whether the model was reasonable, and then performed a path analysis. The analysis proceeded in three stages. In the first stage, we identified correlations among previously described measures via bivariate analysis. The factors identified as potentially significant $(\mathrm{p} \leq 0.1)$ were then considered for inclusion in a multivariate model. In the second stage, we used multivariate linear regression to determine whether self-stigma and other factors were significantly associated with patient activation. Then, factors identified as potentially significant $(\mathrm{p} \leq 0.1)$ during multivariate regression were modelled as having a direct effect on patient activation. A secondary multivariate linear regression was performed to assess whether self-stigma and other factors were associated with HbA1c. In the third stage, with the relationships having been obtained, we conducted path analysis to elucidate the path from self-stigma to patient activation. The conceptual model tested here was proposed in previous studies. ${ }^{8-11}$

We assessed overall model fit using maximum-likelihood analysis, with the following as indicators of fit: goodnessof-fit index (GFI), adjusted GFI (AGFI), comparative fit index (CFI), and root mean square error of approximation (RMSEA). Models for which a chi-square significance test was affirmative and for which the goodness-of-fit indicated consistency, as discussed next, were taken as valid. For GFI, a threshold of 0.95 was used to determine whether the model was an acceptable fit for the data. For AGFI, which is found by adjusting GFI for degrees of freedom, we used the same threshold. RMSEA characterises the amount of misspecification of the model per degree of freedom, and we took a value less than 0.05 to indicate a good fit. ${ }^{24}$

Standardised path coefficients are given for those paths in which all variables were retained. We used SPSS V.23.0 (SPSS Japan) for all preliminary analyses, and AMOS V.23.0 (SPSS Japan) for path analysis. 


\section{Patient involvement}

No patients were involved in designing this study, recruiting study participants, or conducting the study. However, patients were informed that the research team would disseminate the final study results to them.

\section{RESULTS}

Of 259 outpatients with T2DM recruited through their physicians, 218 gave informed consent, for an acceptance rate of $84.2 \%$. All but one of the participants completed the questionnaire. During analysis, we excluded five participants who chose 'strongly disagree' for all 39 items of the SSS-J. This was done to exclude those who either exhibited no self-stigma or for whom it was not clear that the scale was an accurate measure of self-stigma. We also excluded three participants who chose 'strongly agree' for all 13 items of the PAM-13, according to the recommendation of the original scale developers. Therefore, we included data for 209 participants in our final analysis.

Table 1 shows the sociodemographic and clinical characteristics of the 209 participants (168 men (80.4\%); mean age $60.2 \pm 10.1$ years). The mean duration of T2DM was $13.3 \pm 9.4$ years, mean $\mathrm{BMI}$ was $26.3 \pm 5.2$, and mean HbAlc was $7.3 \% \pm 1.2 \%(56 \pm 13.1 \mathrm{mmol} / \mathrm{mol})$. The mean number of diabetes-related complications was $0.57 \pm 0.86$. Oral hypoglycemic agents were the most common form of treatment $(58.9 \%)$. The mean number of years of education was $13.9 \pm 2.3$. Seventeen participants $(8.1 \%)$ scored higher than 10 on the PHQ-9 and exhibited symptoms of depression. Most participants were married (72.2\%). No questionnaire data were missing, and there were no outliers, defined as data points that were 1.5 interquartile ranges below the first quartile or above the third quartile.

In the bivariate analysis, the retained factors (with Pearson's correlation coefficients) for patient activation were BMI $(r=-0.245)$, HbA1c $(r=-0.208)$, self-stigma $(\mathrm{r}=-0.351)$, self-esteem $(\mathrm{r}=0.418)$, self-efficacy $(\mathrm{r}=0.343)$ and depression symptoms $(\mathrm{r}=-0.301)$, and the retained factors for HbA1c were age $(r=-0.314)$ and sex $(r=-0.154)$ (see online supplementary appendix 1). Therefore, these factors were used in further analysis.

In the first multivariate regression analysis, self-stigma $(\beta=-0.19 ; \quad p=0.006), \quad$ self-esteem $\quad(\beta=0.23 ; \quad p=0.005)$, self-efficacy $(\beta=0.10 ; \mathrm{p}=0.199)$, depression symptoms $(\beta=-0.06 ; p=0.411)$ and BMI $(\beta=-0.19 ; p=0.003)$ were associated with patient activation. In the second, age $(\beta=-0.24 ; p=0.001)$ and sex $(\beta=-0.13 ; p=0.063)$ were associated with HbAlc.

We then examined the strengths of the relationships between self-stigma, self-esteem, self-efficacy, depression symptoms, patient activation, HbAlc, and other clinical characteristics via path analysis. Path diagrams show the fundamental relationships among a set of linearly interrelated variables according to hypothesised causal relationships.

Specifically, we used path analysis to examine causal relationships between patient activation and age, sex,
Table 1 Sociodemographic and clinical characteristics of participants $(n=209)$

\begin{tabular}{|c|c|}
\hline Participant characteristics & $\mathbf{N}(\%)$ or mean ( $(\mathbf{S D})$ \\
\hline \multicolumn{2}{|l|}{ Sex } \\
\hline Male & $168(80.4)$ \\
\hline Female & $41(19.6)$ \\
\hline Age (years) & $60.2( \pm 10.1)$ \\
\hline BMI $\left(\mathrm{kg} / \mathrm{m}^{2}\right)$ & $26.3( \pm 5.2)$ \\
\hline Duration of diabetes (years) & $13.3( \pm 9.4)$ \\
\hline \multicolumn{2}{|l|}{ Primary treatment } \\
\hline Oral hypoglycemic agents & $123(58.9)$ \\
\hline Insulin injections & $15(7.2)$ \\
\hline $\begin{array}{l}\text { Insulin injections and oral } \\
\text { hypoglycemic agents }\end{array}$ & $44(21.1)$ \\
\hline $\begin{array}{l}\text { Other injectable medications (other } \\
\text { than insulin) }\end{array}$ & $14(6.7)$ \\
\hline Lifestyle & $13(6.2)$ \\
\hline $\begin{array}{l}\text { Number of diabetes-related } \\
\text { complications }(0-6)^{*}\end{array}$ & $0.57( \pm 0.86)$ \\
\hline $\mathrm{HbA1c}(\%)$ & $7.3( \pm 1.2)$ \\
\hline $\mathrm{HbA} 1 \mathrm{c}(\mathrm{mmol} / \mathrm{mol})$ & $56( \pm 13.1)$ \\
\hline Education (years) & $13.9( \pm 2.3)$ \\
\hline \multicolumn{2}{|l|}{ Marital status } \\
\hline Married & $151(72.2)$ \\
\hline Unmarried/divorced/bereaved & $58(27.8)$ \\
\hline Self-stigma† & $71.1( \pm 16.6)$ \\
\hline Self-esteem ${ }^{\ddagger}$ & $27.7( \pm 3.6)$ \\
\hline Self-efficacy§ & $10.1( \pm 4.1)$ \\
\hline Depression symptoms" & $4.2( \pm 4.3)$ \\
\hline Patient activation ${ }^{\star *}$ & $51.8( \pm 9.3)$ \\
\hline
\end{tabular}

*The Diabetes Complications Index.

†The Japanese version of the scale (SSS-J).

$\ddagger$ The Rosenberg Self-Esteem Scale.

$\S$ The General Self-Efficacy Scale.

ๆThe Patient Health Questionnaire (PHQ-9).

**The Patient Activation Measure (PAM-13).

$\mathrm{BMI}$, body mass index; HbA1c, haemoglobin A1c level.

BMI, self-stigma, self-esteem, self-efficacy, depression symptoms and HbA1c. The results are shown in figure 1, which shows the direct and indirect effects of self-stigma on patient activation. We used statistical analyses and path fitting to examine potential mediators, such as selfesteem, self-efficacy and depression symptoms.

Path analysis showed an excellent fit for a direct relationship between self-stigma and patient activation $\left(\chi^{2}=27.55, \mathrm{df}=20, \mathrm{p}=0.120 ; \mathrm{GFI}=0.97 ; \mathrm{AGFI}=0.94\right.$; $\mathrm{CFI}=0.98$; RMSEA=0.04). Self-stigma had a direct effect on patient activation $(\beta=-0.20 ; \mathrm{p}=0.002)$. Self-stigma also had mediated effects on patient activation by reducing self-esteem $(\beta=-0.22 ; \mathrm{p}<0.001)$, and by reducing selfefficacy $(\beta=-0.36 ; \quad p<0.001)$ and thereby self-esteem $(\beta=0.51 ; p<0.001)$. Lower self-esteem and self-efficacy 


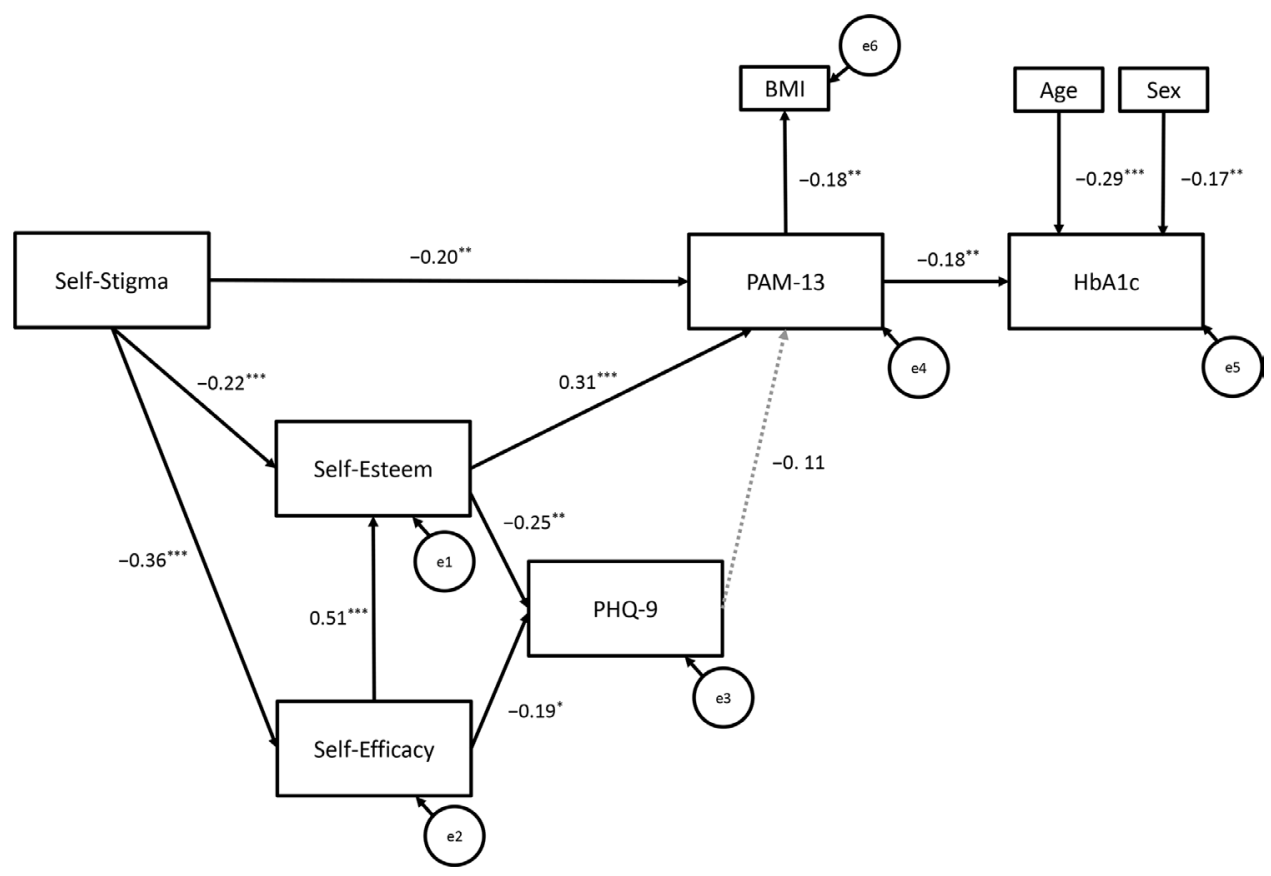

Figure 1 Path model showing relationships between self-stigma, self-esteem, self-efficacy, depression symptoms and patient activation. BMI, body mass index; HbA1c, haemoglobin A1c level; PAM-13, Patient Activation Measure; PHQ-9, Patient Health Questionnaire. $\chi^{2}(20)=27.55, p=0.120 ; \mathrm{GFI}=0.97 ; \mathrm{AGFI}=0.94 ; \mathrm{CFI}=0.98$; RMSEA $=0.04 .{ }^{*} p<.05 ;{ }^{\star \star} p<.01 ;{ }^{\star \star \star} p<.001$.

were related to higher depression symptoms $(\beta=-0.25$, $\mathrm{p}=0.001 ; \beta=-0.19, \mathrm{p}=0.01$, respectively), although depression symptoms were not significantly associated with decreased patient activation $(\beta=-0.11, \mathrm{p}=0.094)$. Selfstigma was statistically related to patient activation, not through depression symptoms, but through lower selfefficacy and self-esteem $(\beta=0.31 ; \mathrm{p}<0.001)$.

\section{DISCUSSION}

In this study, self-stigma was found to affect patient activation in multiple ways. Self-stigma had a direct effect on patient activation, as well as an indirect effect on patient activation via lower self-esteem and self-efficacy. Self-esteem and self-efficacy were associated with depression symptoms. However, depression symptoms were not significantly associated with either patient activation or HbAlc. As for clinical factors, we found a statistically significant effect of patient activation on BMI, and statistically significant effects of age and sex on HbAlc. Our findings are consistent with those from studies of psychiatric patients on the process by which self-stigma affects the attainment of behavioural goals by decreasing self-esteem and self-efficacy. ${ }^{9-11}$ The model described in these previous studies provides a possible explanation for how some patients internalise public stigma and how that self-stigma reduces self-esteem and self-efficacy. Ultimately, this reduces attainment of behavioural goals. In the present study, contrary to what might be expected, depression symptoms were not significantly associated with patient activation. To the best of our knowledge, ours is the first study to report this finding, which indicates that factors underlying depression, such as low self-esteem and low self-efficacy, may be more appropriate intervention targets compared with depression. That is, our path analysis suggests that while interventions aiming to improve patient activation among persons with T2DM should continue to target self-stigma directly, they should also target self-esteem and self-efficacy.

This study has several limitations. First, we used a cross-sectional design, and so we did not examine how the relationships between self-stigma and other tested outcomes change over time. Longitudinal studies are recommended in future research, as such data would test the integrity of the model used here. Second, participants were Japanese outpatients with T2DM. It is wellknown that the perception and experience of stigma surrounding chronic illnesses, and particularly lifestylerelated illnesses, is strongly influenced by society and culture..$^{25}$ The involvement of culture may mean that our results do not extend to persons with T2DM living in other countries, or that they may manifest in different ways, as shown in an investigation of stigma in Australia. ${ }^{26}$ Third, although the prevalence of T2DM in Japan is higher among men $(24.0 \%)$ than women $(13.4 \%),{ }^{27}$ men were overrepresented $(80.4 \%)$ in our sample; the reason for this is unclear. Furthermore, in this study, 17 participants (8.1\%) obtained PHQ-9 scores that were higher than 10. The prevalence of major depressive disorder among persons diagnosed with T2DM in Japan is $10.1 \%^{28}$; this is consistent with the proportions in our study sample. Fourth, we recruited participants from specialist hospitals and clinics. Thus, we did not include persons with T2DM who relied on primary care physicians for treatment, nor individuals who had discontinued treatment. 
A more representative sample of the population in future research would clarify the generalisability of our findings.

Despite these limitations, some clear inferences can be drawn. To better manage patient self-care behaviours so as to optimise treatment outcomes, healthcare professionals should first assess patient levels of self-stigma for T2DM and then strive to encourage self-stigmatised patients to develop a positive personal image of their illness and a sense of accomplishment as they make steady efforts toward daily self-care. Indeed, previous studies have shown that programmes to reduce self-stigma among psychiatric patients improved self-esteem and empowerment, resulting in better adherence to prescribed treatments. ${ }^{29-31}$ Such intervention programmes may lead to similar improvements in treatment adherence in persons with T2DM. However, more research is needed to develop intervention methods for both patients and healthcare professionals, with the goal of reducing selfstigma among persons with T2DM. As shown by our path analysis, future research regarding methods to reduce self-stigma in people with T2DM should consider specific, productive interventions that increase self-esteem and self-efficacy.

Acknowledgements We are grateful to the physicians who recruited patients for this study, the many graduate students who helped with data collection, and particularly all study participants.

Contributors AK conceptualised and designed the study. AK coordinated the study acquired, analysed, interpreted the data and prepared the paper. HH helped to analyse and interpret the data. AK and $\mathrm{HH}$ held primary responsibility for data access. YF, SF, Al, YO, RS, KU, TY and TK made significant contributions to the critical interpretation of the results in terms of important practical content. All authors read and approved the final version of the manuscript.

Funding The authors have not declared a specific grant for this research from any funding agency in the public, commercial or not-for-profit sectors.

Competing interests None declared.

Patient and public involvement Patients and/or the public were not involved in the design, or conduct, or reporting or dissemination plans of this research.

Patient consent for publication Not required.

Ethics approval This study was approved by the Research Ethics Committee of the University of Tokyo Graduate School of Medicine and Faculty of Medicine and was approved and supported by the participating facilities (Approval No. 3269).

Provenance and peer review Not commissioned; externally peer reviewed.

Data availability statement Data are available upon reasonable request. Extra data can be accessed via the Dryad data repository at https://datadryad.org/stash with the https://datadryad.org/stash/dataset/doi:10.5061/dryad.dncjsxkwd

Open access This is an open access article distributed in accordance with the Creative Commons Attribution Non Commercial (CC BY-NC 4.0) license, which permits others to distribute, remix, adapt, build upon this work non-commercially, and license their derivative works on different terms, provided the original work is properly cited, appropriate credit is given, any changes made indicated, and the use is non-commercial. See: http://creativecommons.org/licenses/by-nc/4.0/.

\section{ORCID iDs}

Asuka Kato http://orcid.org/0000-0002-4578-3630

Ryo Suzuki http://orcid.org/0000-0002-2965-6906

\section{REFERENCES}

1 WHO. Global report on diabetes. Geneva: World Health Organization, 2016.
2 UK Prospective Diabetes Study (UKPDS) Group. Intensive bloodglucose control with sulphonylureas or insulin compared with conventional treatment and risk of complications in patients with type 2 diabetes (UKPDS 33). The Lancet 1998;352:837-53.

3 Diabetes Control and Complications Trial Research Group, Nathan DM, Genuth S, et al. The effect of intensive treatment of diabetes on the development and progression of long-term complications in insulin-dependent diabetes mellitus. N Engl J Med 1993;329:977-86.

4 Bodenheimer T, Lorig K, Holman $\mathrm{H}$, et al. Patient self-management of chronic disease in primary care. JAMA 2002;288:2469-75.

5 Hibbard JH, Mahoney ER, Stock R, et al. Do increases in patient activation result in improved self-management behaviors? Health Serv Res 2007;42:1443-63.

6 Browne JL, Ventura A, Mosely K, et al. 'I call it the blame and shame disease': a qualitative study about perceptions of social stigma surrounding type 2 diabetes. BMJ Open 2013;3:e003384.

7 Kato A, Fujimaki Y, Fujimori S, et al. A qualitative study on the impact of internalized stigma on type 2 diabetes self-management. Patient Educ Couns 2016;99:1233-9.

8 Kato A, Fujimaki Y, Fujimori S, et al. Association between self-stigma and self-care behaviors in patients with type 2 diabetes: a crosssectional study. BMJ Open Diabetes Res Care 2016;4:e000156.

9 Corrigan PW, Watson AC, Barr L. The self-stigma of mental illness: implications for self-esteem and self-efficacy. J Soc Clin Psychol 2006;25:875-84.

10 Rüsch N, Angermeyer MC, Corrigan PW. Mental illness stigma: concepts, consequences, and initiatives to reduce stigma. Eur Psychiatry 2005;20:529-39.

11 Link BG, Struening EL, Neese-Todd S, et al. Stigma as a barrier to recovery: the consequences of stigma for the self-esteem of people with mental illnesses. Psychiatr Serv 2001;52:1621-6.

12 Rosenberg M. Society and adolescent self-image. Princeton University Press: Princeton, 1965.

13 Bandura A. Self-efficacy: toward a unifying theory of behavioral change. Psychol Rev 1977;84:191-215.

14 Fincke BG, Clark JA, Linzer M, et al. Assessment of long-term complications due to type 2 diabetes using patient self-report: the diabetes complications index. J Ambul Care Manage 2005;28:262-73.

15 Mak WWS, Cheung RYM. Self-stigma among concealable minorities in Hong Kong: conceptualization and unified measurement. Am J Orthopsychiatry 2010;80:267-81.

16 Kato A, Takada M, Hashimoto H. Reliability and validity of the Japanese version of the self-stigma scale in patients with type 2 diabetes. Health Qual Life Outcomes 2014;12:179.

17 Fujita E, Kuno E, Kato D, et al. Development and validation of the Japanese version of the patient activation measure 13 for mental health. Seishin Igaku 2010;52:765-72.

18 Hibbard JH, Mahoney ER, Stockard J, et al. Development and testing of a short form of the patient activation measure. Health Serv Res 2005;40:1918-30.

19 Hibbard JH, Stockard J, Mahoney ER, et al. Development of the Patient Activation Measure (PAM): conceptualizing and measuring activation in patients and consumers. Health Serv Res 2004;39:1005-26.

20 Mimura C, Griffiths P. A Japanese version of the Rosenberg selfesteem scale: translation and equivalence assessment. J Psychosom Res 2007;62:589-94.

21 Sakano Y, Tohjoh M. The General Self-Efficacy Scale (GSES): scale development and validation. Jpn J Behav Ther 1986;12:73-82.

22 Muramatsu K, Miyaoka H, Kamijima K, et al. The patient health questionnaire, Japanese version: validity according to the miniinternational neuropsychiatric interview-plus. Psychol Rep 2007;101:952-60. PHQ-9 Copyright (1999 Pfizer Inc. all rights reserved.

23 Spitzer RL, Kroenke K, Williams JB, et al. Validation and utility of a self-report version of PRIME-MD: the PHQ primary care study. Primary Care Evaluation of Mental Disorders. Patient Health Questionnaire. JAMA 1999;282:1737-44.

24 Schreiber JB, Nora A, Stage FK, et al. Reporting structural equation modeling and confirmatory factor analysis results: a review. $J$ Educ Res 2006;99:323-38.

25 Scambler G. Health-related stigma. Sociol Health IIIn 2009;31:441-55.

26 Schabert J, Browne JL, Mosely K, et al. Social stigma in diabetes : a framework to understand a growing problem for an increasing epidemic. Patient 2013;6:1-10.

27 Mukai N, Doi Y, Ninomiya T, et al. Trends in the prevalence of type 2 diabetes and prediabetes in community-dwelling Japanese subjects: the Hisayama study. J Diabetes Investig 2014;5:162-9. 
28 Hayashino Y, Ishimaru F, Kadowaki T, et al. Psychological aspects of treatment of diabetes mellitus in the world and the issues that need to be addressed in Japan: the consideration based on the second diabetes attitudes, wishes and needs (DAWN2 ${ }^{\text {TM }}$ ) study. Tounyoubyo 2016;59:652-60.

29 Luoma JB, Kohlenberg BS, Hayes SC, et al. Reducing self-stigma in substance abuse through acceptance and commitment therapy: model, manual development, and pilot outcomes. Addict Res Theory 2008;16:149-65.

30 Maclnnes DL, Lewis M. The evaluation of a short group programme to reduce self-stigma in people with serious and enduring mental health problems. J Psychiatr Ment Health Nurs 2008;15:59-65.

31 Shimotsu S, Horikawa N, Emura R, et al. Effectiveness of group cognitive-behavioral therapy in reducing self-stigma in Japanese psychiatric patients. Asian J Psychiatr 2014;10:39-44. 